\title{
Effect of Therapeutic Massage on Relieving Pregnancy Discomforts
}

\author{
EmanA. El-Hosary ${ }^{(1)}$, Hanan F. Abbas Soliman ${ }^{(2)}$, SamahM. El-Homosy ${ }^{(3)}$ \\ ${ }^{(1)}$ Lecturer of Obstetric and Gynecological Nursing, Faculty of Nursing, Menoufiya University, Egypt. \\ ${ }^{(2)}$ Lecturer of Maternity and Obstetric Nursing, Faculty of Nursing, Ain Shames University, Egypt \\ ${ }^{(3)}$ Lecturer of Obstetric and Gynecological Nursing, Faculty of Nursing, Menoufiya University, Egypt.
}

\begin{abstract}
The Physical and physiological changes occurring during pregnancy associated with negative symptoms which have been shown to impact on the wellbeing of the mother and fetus. Massage therapy was expected to have a positive impact on pregnant women by decreasing stress hormones and potential stressors such as anxiety, leg, back pain and improve mood, sleep and fetal attachment. Aim of the study: To study the effect of therapeutic massage on relieving pregnancy discomforts. Design: An intervention study design was utilized for the study. Setting: this study was conducted at maternal and child health centers for antenatal care at Shebin Elkoom. Sample: A total of 150 pregnant women were recruited in the study. Tools: Four tools were developed and used; 1) A structured interviewing questionnaire, 2) Subjective pain scale (visual-analogue scale [VAS]); 3) sleep scale and 4) anxiety scale. Results: There were statistically significant differences between the two groups regarding pregnancy discomforts as headache, backache, muscle cramp, sleep disturbance and anxiety $(p=.000)$, while there was not statistically significant difference related to joint pain $(p=0.53)$. Women reported that therapeutic massage was very effective on relieving pregnancy discomforts with highly statistically significant differences. Conclusion and recommendations: Therapeutic massage was effective method for reducing discomforts related pain and can be clinically recommended as an alternative, safe and affordable method of pain relief during pregnancy. So it is recommended to raise nurses' awareness regarding use of massage therapies for pregnant women as antenatal routine care. Further studies were needed to apply other non-pharmacological relieving measures for pregnancy discomforts.
\end{abstract}

Keywords: Pregnancy, Massage Therapy

\section{Introduction}

Negative symptoms associated with physical and physiological changes occurring during pregnancy have been shown to impact on the wellbeing of the mother and fetus. Structural stress on the lower back, frequently causes back and leg pain1. Common physical symptoms such as edema, muscle spasm, cramps and fatigue, may lead to difficulty sleeping due to discomfort and body pains 2 . If the symptoms are perceived as stressors by the pregnant women, stress hormones may be released 3, which in turn may affect fetal behavior, such as leading to more time in quiet fetal sleep, less gross body movement during active sleep 4, and less optimal neonatal behavior 5 .

Massage is the manual manipulation of soft body tissues (muscle, connective tissue, tendons, and ligaments) to enhance health and wellbeing6. It is often used for specific reasons, such as relief from pain, stress reduction, massage therapy has the ability to increase the quality of general health and wellbeing in the receiver7. Some natural and alternative therapies have been shown to effectively treat pregnant women without the risks or side effects of some medications. These include deep muscle relaxation, reduced perceived stress, decreased headache and pain 8 .

Massage therapy has been shown to improve circulation and sleep pattern, enhance sense of wellbeing, increase energy and vitality. It has also been shown to decrease chronic back pain reduce anxiety, and improve mood in women experiencing premenstrual syndrome, and to improve sleep pattern9.Studies indicate that massage therapy performed during pregnancy can reduce anxiety, and relieve muscle aches and joint pains 10 .

Modern investigation and research has shown that prenatal massage therapy can be an instrumental ingredient in women's prenatal care and should be given careful consideration11. Studies done in the past 10 years have shown that hormone levels associated with relaxation and stress are significantly altered when massage therapy is introduced to women's prenatal care. This leads to mood regulation and improved cardiovascular health. The evidence strongly suggests there are maternal health benefits when therapeutic massage is incorporated into regular prenatal care 12 .

The benefits of massage can improve overall prenatal health for many pregnant women. Along with the guidance and advice of a prenatal care provider, massage therapy can be incorporated into routine prenatal care as an emotional and physical health supplement shown to improve pregnancy outcome and maternal health 15 .

In the present study, massage therapy was expected to have a positive impact on pregnant women by decreasing pain, anxiety, and improvement sleep.

\section{Significant of the study:}

Aim of the Study: the aim of the current study is to study the effects of therapeutic massage on relieving pregnancy discomforts.

Research hypotheses: To fulfill the aim of the current study the following research hypothesis were formulated.

H1. Pregnant women, who receive massage therapy, will experience less pregnancy discomforts.

\section{Materials And Methods}

Research Design: An intervention study design was utilized to achieve the aim of the current study. 
Setting: The current study was conducted at maternal and child health centers for antenatal care at Shebin Elkoom. During the academic year 2015.

Sample: A total of 150 healthy pregnant women based on rule of sum (number of variables multiply by constant 10) were recruited in the study. Researchers selected pregnant women who met the following inclusion criteria. Women were recruited during their second trimester and the beginning of the third trimester between 14 and 30 weeks of gestation with normal pregnancy condition. The sample was divided randomly into two groups; 75 pregnant women for each group (massage group and no massage group). Exclusion criteria: women who have high risk pregnancy or abnormal fetal condition.

Tools for data collection: Four types of tools were used for data collection.

1) A Structure Interviewing Questionnaire; was developed by the researchers to collect data after extensive literature review related to: 1-a) demographic characteristics (age, name \&educational level); and 1-b) medical and obstetrical data (gestational age).

2) Visual Analogue Scale (VAS): is adopted from Wewers and Lowe (1990) used to assess discomforts as headache, backache, joint pain and muscle cramp pain scores. It consists of a blank line anchored at each end of the line by adjectives that describe the extremes of pain. The anchoring adjectives commonly used are "no pain" (zero score) and "severe pain" (worst possible pain) the top score (10). The validity is concurrent and its reliability was not reported. The woman is asked to place a mark on the line that best indicates the pain being experienced. The dimensions measured by this scale are sensory and affective. This tool takes 2 to 5 minutes to be completed. It was divided into three main parts: the first part graded from 0-3.5 cm which reflects mild pain, the second part graded from 4-7.5 $\mathrm{cm}$ for moderate pain and the third part graded from 8$10 \mathrm{~cm}$ for severe pain. These scores were recorded before and after intervention.

\section{3) Pregnancy Anxiety Scale:}

This scale measured level of anxiety on pregnant woman developed by Benjamin J. Sadock, M.D.(1996), and Book rags, Inc. (2001)the scale consisted of 20 questions that measured woman anxiety towards her pregnancy, fears from labor or any complications that occur during labor, fear from motherhood responsibility, anxiety about economic status or health status. Some modifications done on the scale the key of answer No: 0 Yes: 1 . the cut of score is 10.17

\section{4) Sleep Scale:}

Questions on this 4-item scale are rated on a visual analog anchored at one end with effective sleep responses. Higher scores suggest more effective sleep on the effectiveness scale and lower scores are optimal on the disturbance and supplementary scales and suggest less disturbed sleep and less need for additional sleep, respectively. Satisfactory reliability has been reported for this scale. $\mathbf{1 8}$

\section{Procedures:}

1. Preparatory phase: The researchers received training sessions in conducting massage therapy for one month, two days per week from physiotherapist in the physiotherapy unit at the Menofia university hospital. Moreover, educational videos derived from an internet, was used.

2. Assessment phase (for both groups): Interviews were done at the first day to collect baseline data. The questionnaire was filled in while conducting interviews from Participants required approximately 20 minutes to complete data collection form, then the researcher recorded the participants' telephone number and address in order to follow up them. The questionnaires were filled twice pre and post follow-up.

3. Implementation phase (for Massage Group):

\section{Massage therapy}

Women received massage therapy from 10-20 minutes twice/week over 5 weeks. Massage was learned for women and accompanying person to be done at home. Each session began with the mother in side-lying position, with pillows poisoned behind the back and between the legs for support. The massage was administered in the following sequence:

1. Head and neck: massaging the scalp, making small circles from the forehead, along the hairline and down to temple, and kneading the neck from the base up.

2. Back: using the heel of the hands, moving along the spine; using the palms moving hands with rocking movements from the top of the shoulder blade to the backbone; pressing fingertips, along both sides of the spine from the neck to the backbone and then stroking upward from the hip to the neck; stroking the shoulder muscles(trapezius); inching up the back, using fingertips placed on sides of spine, starting from the hipbone to the neck and then reversing the direction downward using fingertips in a raking fashion; massaging the lower back from the backbone across the waistline using the heel of the palm to make large circles; long gliding strokes from the hip up and over the shoulder.

3.Arms: making long sweeping strokes from the elbow up and over the shoulder; kneading the muscle from above the elbow to the shoulder; stroking from the wrist to the elbow; kneading the muscle between the wrist and the elbow.

4.Hands: massaging the hand using thumbs to make small circles to the palm; on the back of the hand, rubbing between the spaces to the bones; sliding down each finger. 
5.Legs: long sweeping strokes from the knee to the thigh, up and over the hip; kneading the muscles between the knee and thigh; long sweeping strokes from the ankle up toward the knee; kneading the muscles between the ankle and knee; sliding the hand from the Achilles tendon up towards the upper calf, and sliding down to the heel with less pressure several times.

6.Feet: massaging the soles from the toes to the heel with fingers and thumbs and moving back towards the toes; sliding down each toe and rotating toe three times; stroking top of foot towards leg.

The routine was repeated with the mother lying on her other side supported by pillows. These assessments were made at the beginning and after five weeks follow up.

Evaluation phase: pain intensity was evaluated using VAS scale before and after intervention in both groups for headache, backache, muscle cramp and joint pain. Evaluation of Anxiety level by anxiety scale and sleep pattern by sleep scale. All was evaluated after five weeks of using massage therapy.

\section{Content validity and reliability}

Tools were submitted to a panel of five experts in the field of Maternity Nursing, Obstetric Medicine to test the content validity. Modifications were carried out according to the panel judgment on clarity of the sentences and appropriateness of the content. Reliability test was assessed by applying the questionnaire on 10 women using test-retest.

\section{Pilot Study}

It was conducted on $10 \%$ of the study sample, were selected randomly and excluded from the main study sample. Its aim was to evaluate the simplicity and clarity of the tools. It also helped in the estimation of the time needed to fill in the forms. According to the results of the pilot study, simple modifications were done as rephrasing questions or cancelling some questions.

\section{Ethical consideration}

An official permission was granted from the director of the maternal and child health centers. The researchers introduced themselves to the women who met the inclusion criteria and informed them about the purpose of this study in order to obtain their acceptance to share in this study. The researchers ensured that, the study posed no risk or hazards on their health and their participation in the study is voluntary. Pregnant women who were willing to participate in the study and met the inclusion criteria were approached by the researchers and asked for verbal consent to confirm their acceptance, and all events that occurred during data collection were considered confidential.

\section{Statistical design}

Collected data were coded and tabulated using personal computer. Statistical package for social science (SPSS) version 20 was used. Inferential statistics was used to answer research hypotheses. In this research, paired t test was used to compare means of pre and post massage therapy, chi-square to compare between two qualitative variables were used as inferential statistics. Statistical significance was considered at $\mathrm{p}$-value $<0.05$.

\section{Results}

Table (1) showed that women' age ranged between 19 to 33 years old with mean age $(24.4 \pm 4.35)$. As regard educational level $50.7 \%$ and $76.0 \%$ of women with high education while $74.7 \%$ and $74 \%$ were housewives for massage and no massage group respectively, and $62.7 \%$ of women with moderate economical level of both groups.

Table (2). Regarding to obstetric history, it was found that $38.7 \%$ and 26.7 of women were Primigravidas, while $13.3 \%$ and $24 \%$ of women delivered with caesarian section of both groups. As regard pregnancy complications $37.3 \%$ and $40 \%$ of women had anemia for massage and no massage groups respectively. Furthermore, the mean of present gestational age was $26.3 \pm 3.77$ and $26.6 \pm 3.81$ for both groups.

Fig (1): indicated that the most common pregnancy discomforts in the second trimester of pregnancy were headache, backache, sleep disturbance, muscle cramp, anxiety, and joint pain as reported by women in the studied groups.

Fig (2). Regarding to pain degree in the no massage group, it was found that; $12 \%, 13.3 \%$ and $33.3 \%$ of the pregnant women had severe pain related to backache, joint pain and muscle cramp respectively. While $89.3 \%, 88 \%, 62.7 \%$ and $52 \%$ of them had moderate pain related to headache, backache, joint pain and muscle cramp respectively. There was no or minimal relieve of discomforts with the no massage group.

Fig (3): At the initial assessment, before intervention for the massage group; 4\%, 17.3\%, 17.3\% and 41.3\% of women had severe pain regarding headache, backache, joint pain and muscle cramp respectively. While $84 \%, 82.7 \%, 60 \%$ and $48 \%$ of them had moderate pain respectively. At the final assessment, women had no severe pain for all the discomforts. While, $24 \%$ and $36 \%$ of women had moderate pain regarding headache and joint pain respectively. Also, $37.3 \%, 62.7 \%, 64 \%$ and 26.7 of women had mild pain regarding headache, backache, joint pain and muscle cramp respectively, while 38.7\%, 37.3\%, $73.3 \%$ of women had no pain regarding headache, backache and muscle cramp respectively, which indicated there was observed improvement in the discomforts with the massage group.

Table (3) showed that at final assessment; massage group is more effective on relieving pregnancy discomforts as headache, backache, joint pain, muscle cramp, sleep disturbance and anxiety than no massage group with highly statistically significant differences, while there was not statistically significant difference related to joint pain.

Table (4): revealed that there was high significant improvement on mean score of pregnant women discomforts after using massage therapy (for massage group).

Table (5): illustrates that $38.7 \%, 73.3 \%, 61.3 \%$ and $50.7 \%$ of pregnant women reported that massage therapy was very effective on relieving their discomforts as headache, backache, muscle cramps and sleep disturbance respectively. While 
$100 \%$ and $50.7 \%$ of pregnant women reported that massage therapy was effective regarding anxiety and joints pain respectively.

Table (1): Demographic characteristics of the studied samples.

\begin{tabular}{|c|c|c|c|c|}
\hline \multirow[t]{2}{*}{ Items } & \multicolumn{2}{|c|}{ Massage group } & \multicolumn{2}{|c|}{ No Massage group } \\
\hline & No. & $\%$ & No. & $\%$ \\
\hline \multirow[t]{5}{*}{ Age: } & & & & \\
\hline & 9 & 25.3 & 21 & 28.0 \\
\hline & 39 & 38.7 & 27 & 36.0 \\
\hline & 18 & 24.0 & 19 & 25.3 \\
\hline & 9 & 12.0 & 8 & 10.7 \\
\hline Range 19-33 Mean \pm SD & \multicolumn{3}{|c|}{$24.4 \pm 4.36$} & $24.2 \pm 4.3$ \\
\hline \multicolumn{5}{|l|}{ Educational Level: } \\
\hline Illiterate. & 10 & 13.2 & 10 & 13.3 \\
\hline Read \& write. & 9 & 12.0 & 11 & 14.7 \\
\hline Secondary. & 18 & 24.0 & 19 & 25.3 \\
\hline University. & 38 & 50.7 & 35 & 46.7 \\
\hline \multicolumn{5}{|l|}{ Occupation: } \\
\hline Housewife. & 56 & 74.7 & 57 & 76.0 \\
\hline Employee & 19 & 25.3 & 18 & 24.0 \\
\hline \multicolumn{5}{|l|}{ Husband's educational level: } \\
\hline Illiterate. & 10 & 13.3 & 6 & 8.0 \\
\hline Read \& write. & 9 & 12.0 & 9 & 12.0 \\
\hline Secondary. & 27 & 36.0 & 37 & 49.3 \\
\hline University. & 29 & 38.7 & 23 & 30.7 \\
\hline \multicolumn{5}{|l|}{ Economic status: } \\
\hline Low & 10 & 13.3 & 8 & 10.7 \\
\hline Moderate & 47 & 62.7 & 47 & 62.7 \\
\hline High & 18 & 24.0 & 20 & 26.6 \\
\hline
\end{tabular}

Table (2): Previous Obstetric History of the Studied Samples.

\begin{tabular}{|c|c|c|c|c|}
\hline \multirow{2}{*}{ Obstetric history } & \multicolumn{2}{|c|}{ Massage group } & \multicolumn{2}{|c|}{ No Massage group } \\
\hline & No. & $\%$ & No. & $\%$ \\
\hline $\begin{array}{l}\text { No. of pregnancies: } \\
<2 \\
2-3 \\
>3\end{array}$ & $\begin{array}{c}29 \\
37 \\
9\end{array}$ & $\begin{array}{l}38.7 \\
49.3 \\
12.0\end{array}$ & $\begin{array}{l}20 \\
39 \\
16\end{array}$ & $\begin{array}{l}26.7 \\
52.0 \\
21.3\end{array}$ \\
\hline $\begin{array}{l}\text { No. of previous deliveries: } \\
\text { None } \\
<2 \\
2-3 \\
>3 \\
\end{array}$ & $\begin{array}{c}29 \\
27 \\
19 \\
0 \\
\end{array}$ & $\begin{array}{c}38.7 \\
36.0 \\
25.3 \\
0\end{array}$ & $\begin{array}{c}20 \\
26 \\
29 \\
0\end{array}$ & $\begin{array}{c}26.7 \\
34.7 \\
38.6 \\
0 \\
\end{array}$ \\
\hline $\begin{array}{l}\text { Type of previous deliveries: } \\
\text { NVD } \\
\text { NVD with episiotomy. } \\
\text { CS }\end{array}$ & $\begin{array}{l}19 \\
17 \\
10\end{array}$ & $\begin{array}{l}25.3 \\
22.7 \\
13.3\end{array}$ & $\begin{array}{l}18 \\
19 \\
18\end{array}$ & $\begin{array}{l}24.0 \\
25.3 \\
24.0\end{array}$ \\
\hline $\begin{array}{l}\text { Previous pregnancy complications: } \\
\text { Only anemia }\end{array}$ & 28 & 37.3 & 30 & 40.0 \\
\hline $\begin{array}{l}\text { Present pregnancy gestational age: } \\
\text { Range } 20-32 \text { weeks } \quad \mathrm{M} \pm \mathrm{SD}\end{array}$ & \multicolumn{2}{|c|}{$26.3 \pm 3.77$} & \multicolumn{2}{|c|}{$26.6 \pm 3.81$} \\
\hline
\end{tabular}

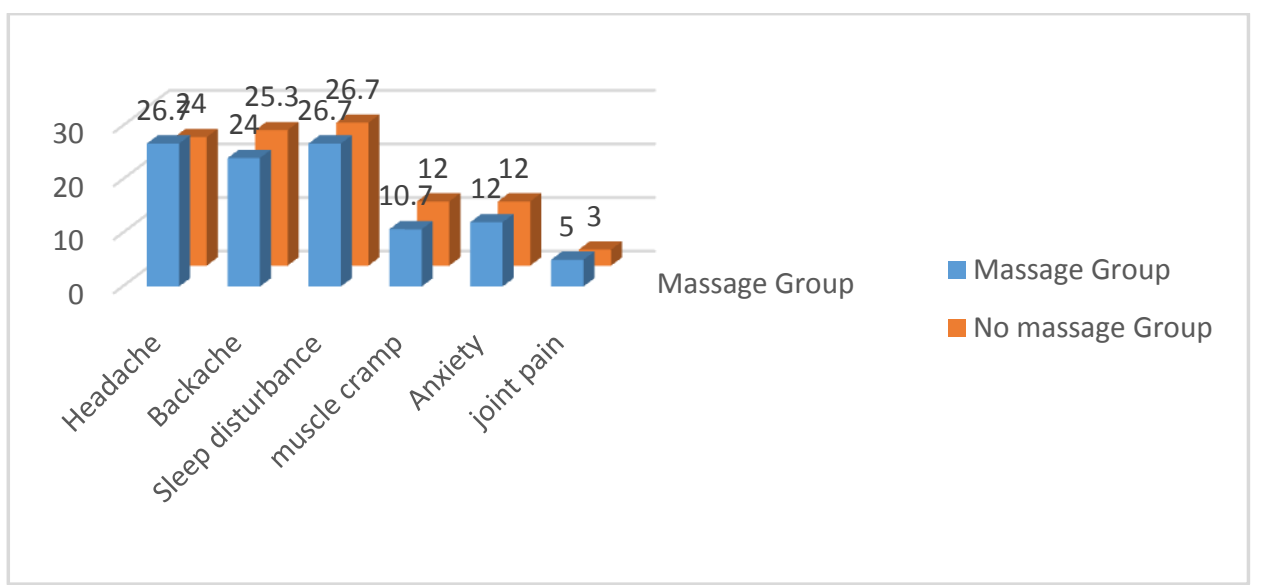

Fig (1) Present Pregnancy Complaints of the Studied Samples. 


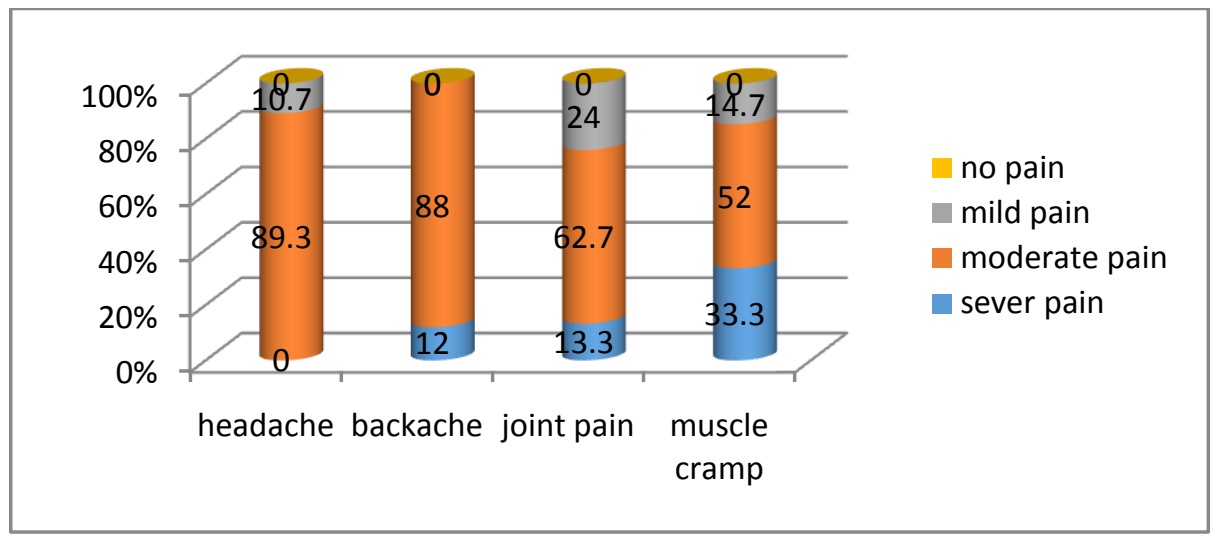

Fig. (2): Degree of pain related to Pregnancy discomforts for no massage group at final assessment

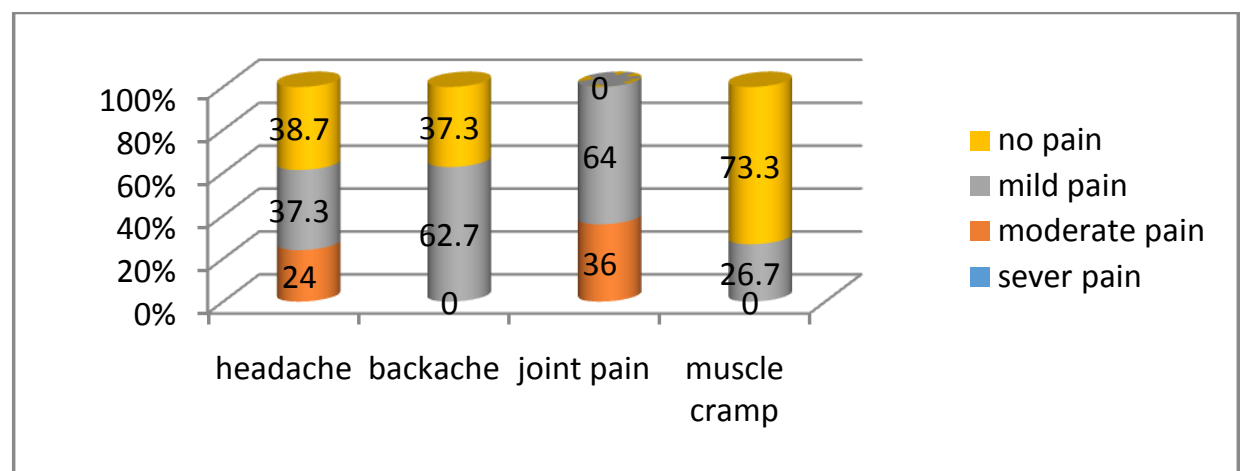

Fig. (3): Degree of pain related to Pregnancy discomforts for massage group at final assessment.

Table (3): Pregnancy discomforts score among massage and no massage groups at final assessment.

\begin{tabular}{|l|c|c|c|c|}
\hline Pregnancy Discomforts & $\begin{array}{c}\text { Massage group } \\
(\mathrm{n}=75) \mathbf{M} \pm \mathbf{S D}\end{array}$ & $\begin{array}{c}\text { No massage group } \\
(\mathrm{n}=75) \mathbf{M} \pm \mathbf{S D}\end{array}$ & $\mathrm{t}$-value \\
\hline$\downarrow$ Headache & $2.14 \pm 0.78$ & $1.1 \pm 0.31$ & 10.69 & $.000^{* *}$ \\
\hline$\downarrow$ Backache & $2.37 \pm 0.48$ & $.88 \pm 0.32$ & 22.04 & $.000^{* *}$ \\
\hline$\downarrow$ Joint pain & $1.64 \pm 0.48$ & $1.1 \pm 0.60$ & 5.96 & 0.535 \\
\hline$\downarrow$ Muscle cramp & $2.73 \pm 0.44$ & $0.81 \pm 0.67$ & 20.6 & $.004^{*}$ \\
\hline$\downarrow$ Sleep disturbance & $3.41 \pm 0.495$ & $2.12 \pm 0.63$ & 13.89 & $.000^{* *}$ \\
\hline$\downarrow$ Anxiety & $16.0 \pm 2.11$ & $6.89 \pm 3.58$ & 18.99 & $.000^{* *}$ \\
\hline
\end{tabular}

** Level of significance at $p \leq 0.05$, highly significant difference at $p \leq 0.01$

Table (4): Pre and post score of pregnancy discomforts for the massage group.

\begin{tabular}{|l|c|c|r|c|}
\hline \multicolumn{1}{|c|}{ Pregnancy Discomforts } & $\begin{array}{c}\text { Pre massage therapy } \\
\mathrm{n}=75 \mathrm{M} \pm \mathrm{SD}\end{array}$ & $\begin{array}{c}\text { Post massage therapy } \\
\mathrm{n}=75 \mathrm{M} \pm \mathrm{SD}\end{array}$ & $\mathrm{t}$ & $\mathrm{p}$-value \\
\hline Headache & $1.92 \pm 0.39$ & $0.85 \pm 0.78$ & 11.890 & $.000^{* *}$ \\
\hline Backache & $2.17 \pm 0.38$ & $0.62 \pm 0.48$ & 25.395 & $.000^{* *}$ \\
\hline Joint pain & $1.94 \pm 0.63$ & $1.36 \pm 0.48$ & 6.575 & $.000^{* *}$ \\
\hline Muscle cramp & $2.30 \pm 0.65$ & $0.26 \pm 0.44$ & 20.515 & $.000^{* *}$ \\
\hline Sleep disturbance & $2.88 \pm 0.59$ & $1.53 \pm 0.5$ & 10.3 & $.000^{* *}$ \\
\hline Anxiety & $12.87 \pm 4.05$ & $3.82 \pm 2.52$ & 23.86 & $.000^{* *}$ \\
\hline
\end{tabular}

** Level of significance at $p \leq 0.05$, highly significant difference at $p \leq 0.01$

Table (5): Effectiveness of massage therapy on pregnancy discomforts as reported by women.

\begin{tabular}{|l|c|c|c|c|c|c|c|c|}
\hline \multirow{2}{*}{ Pregnancy discomforts } & \multicolumn{2}{|c|}{ Very effective } & \multicolumn{2}{|c|}{ Effective } & \multicolumn{2}{c|}{ Ineffective } & \multicolumn{2}{c|}{ Ineffective at all } \\
\cline { 2 - 9 } & No. & $\%$ & No. & $\%$ & No. & $\%$ & No. & $\%$ \\
\hline Headache & 29 & 38.7 & 27 & 36.0 & 19 & 25.3 & 0 & 0 \\
\hline Backache & 55 & 73.3 & 20 & 26.7 & 0 & 0 & 0 & 0 \\
\hline Joints pain & 0 & 0 & 38 & 50.7 & 27 & 36.0 & 10 & 13.3 \\
\hline Muscle cramp & 46 & 61.3 & 20 & 26.7 & 9 & 12.0 & 0 & 0 \\
\hline Sleep disturbance & 38 & 50.7 & 27 & 36.0 & 10 & 13.3 & 0 & 0 \\
\hline Anxiety & 0 & 0 & 75 & 100 & 0 & 0 & 0 & 0 \\
\hline Total & $\mathbf{1 6 8}$ & $\mathbf{2 2 4}$ & $\mathbf{2 0 7}$ & $\mathbf{2 7 6 .}$ & $\mathbf{6 5}$ & $\mathbf{8 6 . 6}$ & $\mathbf{1 0}$ & $\mathbf{1 3 . 3}$ \\
\hline
\end{tabular}

IV. Discussion:

Pregnancy induces a number of physiological, anatomical and biochemical changes. Many of these changes are accompanied by physical symptoms which are specific to pregnancy, although pregnancy symptoms may be considered a normal part of an uncomplicated pregnancy, they still cause significant discomfort for women (Rodriguez et al, 2001 and Yates, 2010). 
Drug therapy used to treat the symptoms during pregnancy might affect fetal development. Some natural and alternative treatments have been shown to effectively treat pregnant women without the risks or side effects associated with some medications. Massage is a beneficial method to relieve the pain perceptions, without side effects and cost free methods as compared to pharmacological methods. The intention of this study was to study the effects of therapeutic massage on pregnancy discomforts.

The current study revealed that pregnant women' age ranged between 19 to 33 years old with mean age (24.4 \pm 4.36). The mean gestational age is $26.3 \pm 3.77$ and $26.6 \pm 3.81$ for the massage and no massage groups respectively.

Concerning the pregnancy discomforts, the present study indicated that headache $26.7 \%$ and $24 \%$, backache $24 \%$ and $25.3 \%$, joint pain $5 \%$ and $3 \%$, muscle cramp $10.7 \%$ and $12 \%$, sleep disturbance $26.7 \%$ and anxiety are the most common discomforts during the second trimester of the massage and no massage groups respectively. In accordance with (Yates, 2010), who stated that the physical and emotional demands of pregnancy can be challenging for women. From early signs and symptoms such as nausea and fatigue to the enormous weight bearing adjustments of the muscular skeletal system; exaggerated lumbar lordosis and pelvis rotation often causing low back pain, the stretching and separation of abdominal muscles as the uterus increases in size, plus huge changes in neuroendocrine functioning and demands on energy metabolism affecting most physiological systems, Many women experience some degree of anxiety, concern and fear regarding their own health and that of their babies, as well as the approaching labor.

This may be related to during pregnancy, there are many changes that occur in a woman's body. Her body needs to adjust to these changes in order to provide for fetal needs. But these changes cause discomforts for her.

Results of the present study indicated that massage therapy had an effective role in reducing pregnancy discomforts related pain. This is supported by (Martin, 2013) who stated that therapeutic massage for pregnancy discomforts is a natural way to relieve pain, anxiety, and improve sleep. It is safe, non-invasive, and economical and cost free. Also, Ganzer, 2014 reported that pregnancy is a very exciting time filled with new experiences and lots of new information. The pregnant woman need to do everything in her power to support a happy and healthy pregnancy. Massage Therapy can be a wonderful adjunct to healthy lifestyle. This is may be due to massage therapy provide distraction from pain. Helps the mother remains in a more relaxed state and respond more positively to the discomforts related pain. Massage may also change the way the brain senses pain. A good massage can temporarily make the brain forget about other aches.

Concerning to pregnant women complaints, it was observed that there was improving of women condition related to headache and sleep disturbance. In the same line with (Field et al, 1999) who found that Twenty-six adults with migraine headaches were randomly assigned to a wait-list control group or to a massage therapy group, who received to 30-minute massages per week for five consecutive weeks. The massage therapy subjects reported fewer distress symptoms, less pain, more headache free days, fewer sleep disturbances and they showed an increase in serotonin levels. In the same line with a follow up study focused on just massage and relaxation, indicating that massage and relaxation interventions might have a positive impact on pregnant women by decreasing stress hormones and potential stressors, improved mood, and sleep. After their treatment period there was less disruption of sleep for the massage therapy group and an increase in supplemental daytime sleep for the relaxation group as measured using a visual analog sleep scale (Hollenbach et al, 2013).

Therefore, the present study adds support to the notion that the effect of massage on pain may be clinically worthwhile. Effective Massage improves circulation and releases hormone that lessens pain in the affected area, so free headache will be improving the sleep and decreases insomnia.

The experimental study conducted by (Field, 2010), determined that massage therapy is effective for reducing pregnant women's anxiety, sleep disturbance, and back pain. This was in agreement of the present study findings where the mean of backache related pain was before massage $2.17 \pm 0.38$ and after massage it was $0.6267 \pm 0.48$ with statistically significant differences. Also, in accordance with (Oswald and Higgins, 2013) who stated that massage therapy and chiropractic care, including spinal manipulation, are highly safe and effective evidence-based options for pregnant women suffering from mechanical low back and pelvic pain. This is due to therapeutic massage aid in relaxation of the body muscles, when done in circular motion help in releasing hormones such as endorphin and serotonin which decrease the sense of pain and regulate the mood, so improving the woman general condition.

This was in agreement with (Field, 2015) of Touch Research Institute in the University of Miami Medical School, Florida, and Fielding Graduate University, has already provided a surreptitious amount of medical research data on how massage therapy improves the overall health of the pregnant women and how they can alleviate the pain. Also, George, et al 2013. Stated that a combination of manual therapy, exercise, and patient education reduces pain and disability when applied at 24-33 weeks' gestation. A multimodal approach to low back and pelvic pain in mid pregnancy benefits patients' more than standard obstetric care.

The current study findings indicated that the mean score of joint pain and muscle cramp before massage was $1.94 \pm$ 0.63 and $2.30 \pm 0.65$ and after massage therapy was $1.36 \pm 0.48$ and $0.26 \pm 0.44$ respectively with statistically significant differences. In the same line with a study conducted by (Rowall, 2016) which determined that pregnancy massage has many benefits by helping increase elasticity and range of motion in the joints and muscles. This may be due to massage can increase blood flow to stiff joints and muscles, which are warmed by the extra circulation. Also, triggers the release of natural painkillers called opioids in the brain which decrease pain.

Also, the mean score of sleep disturbance and anxiety in the present study was $2.88 \pm 0.59$ and $12.87 \pm 4.05$ before massage to $1.53 \pm 0.5$ and $3.82 \pm 2.52$ after massage respectively with statistically significant differences. The findings were in agreement with a study conducted by Nihira, 2010 who determined the effectiveness of massage therapy that lowered anxiety, decreased back and leg pain, and improved sleep during pregnancy. Also congruent with (Shelley, 2007) that determined the massage during pregnancy helped to alleviate pain, improve sleep and generally boost an expecting mother's mood.

Association of massage therapy, 2014 reported that anxiety, headache, and arthritis are the most well-established effects of massage therapy with evidence for the crossing multiple presenting conditions and populations. A similar study 
conducted by (Chang, 2002) found that reduced levels of pain and anxiety in recipients of massage during pregnancy. The author emphasizes the psychosocial value of massage as a pain and anxiety relieving strategy, and suggest that it may the caring and supportive aspect of giving massage that carries the therapeutic value. The study conducted by (Canadian Agency for Drugs and Technology in Health 2013) determined that Massage therapy was effective in treatment of insomnia by using case series with either posttest outcome. This is due to massage therapy help in decreasing stress so relieving anxiety.

The pregnant women in the current study reported that massage therapy was effective in relieving their discomforts during pregnancy in the second trimester. This was in agreement with (Woolston, 2016), which reported that Massage therapy relaxes muscle tissue, which reduces painful contractions and spasms. Massage can also reduce nerve compression when muscles are contracted, they sometimes compress the nerves around them. When these muscles are relaxed, the nerves are no longer compressed, and, in theory, can get proper nutrients and operate more efficiently. The nerves can assume their normal work of transmitting messages to and from the brain, which improves functioning of the muscles and organs. And although massage has been found useful for relieving the aches and stiffness that show up during pregnancy, some experts recommend waiting until the second trimester to receive prenatal massage.

\section{Conclusion:}

Based on the present study findings, it was concluded that the massage therapy had significant reduction in pregnancy discomforts like headache, backache, joint pain, muscle cramp, sleeping disturbance and anxiety during pregnancy as compared to no massage. Further investigations are necessary to replicate the beneficial findings on fetus and newborn. Therefore, Massage therapy can be readily implemented in routine antenatal care. It proved to be an effective measure. Moreover, it could be used by the women who had complaint of another discomforts during pregnancy without taking any medications or analgesics.

\section{Recommendations:}

Based on the study findings, the following were recommended; 1) - Encourage all pregnant women to practice massage therapy during pregnancy and delivery to improve pregnancy outcomes. 2) - Training program for health care provider on how to apply non-pharmacological pain management during pregnancy. 3) - conduct a similar study on subjects who undergo pregnancy with another discomforts during different trimesters and with large sample size and different setting to generalize the results. 4) Educational program facilities and methods about Non-pharmacological methods as; lectures, handout, and videos should be developed and become accessible to all pregnant women in outpatient clinic.5) This area of research needs additional efforts in order to expand the evidence base on the association between non-pharmacological methods and pain relieve during pregnancy. And 6) future research to increase nurses' awareness regarding use of nonpharmacological methods as pain relievers during pregnancy, labor and puerperium.

\section{References}

[1]. Heliovaara M. Risk factors for low back pain and sciatica. Ann Med 1989;21:257-64

[2]. Hertz G, Fast A, Feinsilver S, et al. Sleep in normal late pregnancy. Sleep 1992;15:246-5

[3]. Smith R, Cubis J,Brinsmead M, et al, Mood changes, Obstetric experience and alterations in plasma cortisol, beta-endorhpin and corticotrohpine releasing hormone during pregnancy and the puerperium. J Psychosom Res 1990;34:53-69

[4]. Groome L, Swiber M, Bentz L, et al. Maternal anxiety during pregnancy: effect on fetal behavior at 38 to 40 weeks of gestation. J Dev Behav Pediatr 1995;16:391-6

[5]. Abranms SM, Field T, Scafidi F, et al. Maternal stress effects on neonates. Infant Behav Dev1998; in press

[6]. Field T, Grizzle N, Scafidi F, et al. Massage and relaxation therapies, effects on pregnant woman. 1996;31:903-911

[7]. Field T, Morrow C, Valden C, et al. Massage therapy and the pregnant woman. J Am Acad. 1999;31:125-31

[8]. Ironson G, Field T, Scafidi F, et al. Massage therapy as an alternative therapy. Int J Neurosci 1996;84:205-17

[9]. Hernandez-Reif M, Martinez A, Field T, et al. Premenstrual sundrome symptoms are relieved by massage therapy. J Psychosome Obstet Gynaecol 1999; in press

[10]. Hernandez-rief M, field T, Krasegor J, et al. muscle joint pain is reduced following massage therapy. 1999

[11]. Jones N, Field T, Fox NA, et al. Massage therapy in routine antenatal care. 2012

[12]. Field T, Hernandez-rief M, Hart S, et al. Pregnant women benefit from massage therapy. J Psychosom Obstet Gynecol 1999;20:31-38

[13]. .T. Field, M. Hemandez-Reif, S. Hart, H. Theakston, S. Schanberg, and C. Kuhn Pregnant women benefit from massage therapy

[14]. 1999, Vol. 20, No. 1, 31-38

[15]. .Wang SM, Dezinno P, Fermo L, et al. Complementary and alternative medicine for low-back pain in pregnancy: a cross-sectional survey. J. Altern. Complement. Med.2005;11:459-464.

[16]. Field T, Diego M, Hernandez-Reif M, Deeds O, Fiqueiredo B. Pregnancy massage reduces prematurity, low birthweight and postpartum depression. Infant Behav. Dev.2009;32:454-460.

[17]. Spielberger CD. Visual analog scale. Current Trends in Theory and Research, NewYork: Academic press, 1972

[18]. Snyder-Halperin S, Verran JA. Instrumentation to describe subjective sleep charatrestics in healthy sbjects. Res Nurs Health 1987;10:155-63

[19]. .Kelly Martin.The Therapeutic Effects of Massage Therapy on Pregnancy Outcomes,University of Minnesota Integrative Medicine Course - Winter Semester 2013

[1]. Adams, J. (2009): Women's Use of Complementary and Alternative Medicine during Pregnancy. A Critical Review of Literature,36(3):237 245 www.interscience.wiley.com

[2]. Association of Massage Therapy (2014): Effects of Massage Therapy with Evidence for Crossing Multiple Presenting Conditions and Populations.

[3]. Canadian Agency for Drugs and Technologies in Health (2013): Massage Therapy is Effective in Treatment of Insomnia by Using Case Series with Either Posttest Outcomes.

[4]. Chang. M (2002): Effects of Massage on Pain and Anxiety during Pregnancy, randomized controlled trial in Taiwan. Journal of advanced nursing 38(1):68-73 www.interscience.willey.com

[5]. Elhosary. E (2005): An investigation into some factors related to anxiety and depression during pregnancy, pregnancy anxiety scale, appendix11 Master theses. 
[6]. Field.T (2007): Massage Therapy Reduces Pain in Pregnant Women. Journal of Bodywork and Movement Therapies (12): 146-150 www.intl.elsevierhealth.com

[7]. Field.T (2010): Pregnancy and Labor Massage, Mar; 5(2):177-181

[8]. Field T, Diego M, Hernandez-Reif M, Deeds O, Fiqueiredo B (2009): Pregnancy massage reduces prematurity, low birthweight and postpartum depression. Infant Behav. Dev.;32:454-460.

[9]. Field T, Grizzle N, Scafidi F, (2015): Massage and relaxation therapies, effects on pregnant woman.; 31:903-911

[10]. Field, T., Hemandez-Reif, M., Hart, S., Theakston, H., Schanberg, S., \& Kuhn, C. (1999): Pregnant women benefit from massage therapy. Journal of Psychosomatic Obstetrics \& Gynecology, 20(1), 31-38

[11]. Ganzer.M (2014): Prenatal massage, A text book of pregnancy, labor, and postpartum. Google Books 30 July http:// books google.Ca/books?

[12]. George, J. W., Skaggs, C. D., Thompson, P. A., Nelson, D. M., Gavard, J. A., (2013): A randomized controlled trial comparing a multimodal intervention and standard obstetrics care for low back and pelvic pain in pregnancy. American journal of obstetrics and gynecology, 208(4), 295-e1

[13]. Hollenbach, D., Broker, R., Herlehy, S., \& Stuber, K. (2013). Non-pharmacological interventions for sleep quality and insomnia during pregnancy: a systematic review. The Journal of the Canadian Chiropractic Association, 57(3), 260

[14]. Gould D.et al. (2001): Visual Analogue Scale (VAS). Journal of Clinical Nursing; 10:697-706

[15]. Martin.K (2013): The Therapeutic Effects of Massage Therapy on Pregnancy Outcomes, University of Minnesota Integrative Medicine Course Winter Semester. http:// takingcharge.csh.umn.edu

[16]. Micozzi.M (2001): Fundamentals of Complementary and Alternative Medicine. $2^{\text {nd }}$ Ed. Pennsylvania, Churchil Livingstone.

[17]. Nihira. B (2010): Assessing the Efficacy of Massage Therapy on Pregnancy: Adding Qualitative Research Methods to the Gold Standard. Journal of Alternative and Complementary Medicine 8(3):275-281.

[18]. Oswald, C., Higgins, C. C., \& Assimakopoulos, D. (2013): Optimizing pain relief during pregnancy using manual therapy. Canadian Family Physician, 59(8), 841-842.

[19]. Rief M, field T, Krasegor J, (1999): muscle joint pain is reduced following massage therapy.

[20]. Rodriguez, A., Bohlin, G., \& Lindmark, G. (2001). Symptoms across pregnancy in relation to psychosocial and biomedical factors. Acta obstetricia et gynecologica Scandinavica, 80(3), 213-223.

[21]. Rowall, B. (2016). Benefits of massage therapy.com. Recovered 3/25/2013 from http://www.benefits-of-massage-therapy.com/maternity-massage.html

[22]. Shelley.M (2007): Effect of Massage Therapy on Pregnancy Outcomes; Therapeutic effects of Massage on pain, sleep, and mood; 34:53-69

[23]. Simpson.K (2010): The Value of Massage during Pregnancy and Childbirth: An Exploration of Practitioners views; University of Wesminster

[24]. Snyder-Halperin S, Verran JA (1987): Instrumentation to describe subjective sleep characteristics in healthy subjects. Res Nurs Health; 10:155-63

[25]. Tiran. D (2007): Complementary Therapies in Pregnancy. Midwives and Obstetricians Appreciation of Risk, Complementary Therapies in Clinical Practice (12):126-131 www.sciencedirect.com

[26]. Wang, S. M., Zinno, P. D., Fermo, L., William, K., Caldwell-Andrews, A. (2005). Complementary and alternative medicine for low-back pain in pregnancy: a cross-sectional survey. Journal of Alternative \& Complementary Medicine, 11(3), 459-464

[27]. Woolston. C by HealthDay, (2016): Massage for Pain Relief http://consumer.healthday.com/

[28]. Yates, S., (2010). Pregnancy and Childbirth A holistic approach to massage and bodywork. UK: Churchill Livingstone Elsevier. 